\title{
Operations Strategy: A Broader View Of Threading The Vision To The Customer
}

Philip E. Burian, Briar Cliff University, USA

Francis R. "Skip” Maffei, III, Jones International University, USA

\begin{abstract}
In today's turbulent business environment, providing services, products, and solutions that meet customer needs and demands is a major challenge for all businesses. To be more competitive, companies are placing greater emphasis on lowering costs, improving quality, and reducing product cycle-time. Many different approaches, frameworks, and models are being used to guide businesses in their endeavors to move to the next level of productivity and excellence. This paper proposes an integrated framework that can assist business executives in evaluating and integrating their organizations in order to improve their operational profile.
\end{abstract}

Keywords: Operations Strategy; Operations Management; Strategic Management

\section{INTRODUCTION}

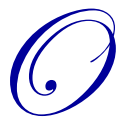

perations Management and Strategy have been directly associated with manufacturing, logistics, and supply chain. This paper introduces an Operations Strategy Framework and Assessment Tool that can be implemented to assess an organization for effectiveness and efficiency and, more importantly, to thread the organization's vision, objectives, strategies, processes, resources, products, and services to the customer (Brown, Squire, \& Lewis, 2010).

\section{OPERATIONAL DIFFERENCES}

There are a number of operational differences between a Manufacturing and a Service Delivery organization (Jui-Sheng, Kim, Yao-Chen, \& Nai-Chi, 2010). A manufacturing organization builds, assembles, tests, and distributes products with little to no interaction with the end customer or consumer. Examples of manufacturing organizations include automobiles, electronic equipment, and information systems platforms.

Conversely, a Service Delivery organization directly interacts with the end customer or consumer providing a packaged or bundled suite of products and services. Examples of Service Delivery organizations include Healthcare, Information Technology, Help Desk, Service and Support, and Software Development.

\section{Manufacturing Operating Models, Key Functions, and Core Processes}

This section describes the more common operating models, and key functions, and outlines some core business processes typically used by manufacturing organizations.

\section{Operating Models}

Two common operational models are found in manufacturing organizations. The first is what is referred to as the Classical model. Some of the characteristics of this model include assembly line operations, mass production, raw materials acquisition, and warehousing and distribution. This model relies heavily on mechanization and automation of processes and equipment operation. The second and more recent model is what is referred to as the Lean model which can be viewed as a more improved model that optimizes people, process, innovation, and technology in a manner that reduces waste and facilitates an environment of high efficiency at the lowest possible 
costs. This model relies heavily on the use of information technology to support inventory control, production scheduling, and resource management. This increased level of automation, innovation, and tracking is critical to reduce the overhead costs associated with the typical classic manufacturing model.

\section{Key Functions}

Some of the key functions that support any manufacturing organization, regardless of the operational model, include purchasing, warehousing, facilities, operations, and engineering. The primary differences between the Classical and the Lean manufacturing models are the amount and extent of automation, streamlining of processes, funds management, and people and technology integration (Cao, 2004).

\section{Core Processes}

Some of the more common core processes that support any manufacturing organization, regardless of the operational model, include contracts, proposals, shipping, receiving, storage, inventory, scheduling, assembly, test, inspection, maintenance, facilities, and capacity planning (Ivanov, 2010). Once again, the primary differences between the Classical and Lean manufacturing models are the amount and extent of automation, streamlining of processes, and people and technology integration (Corbett, 2008). In the Lean model, processes are optimized and the use of best practices and innovation are critical in order to achieve high efficiency.

\section{Service Delivery Operating Models, Key Functions, and Core Processes}

This section describes the more common operating models, lists some key functions, and outlines some core business processes for a Service Delivery organization.

\section{Operating Models}

Two common operational models are found in Service Delivery organizations. The first is what is referred to as the Customer-Centric model. Some of the characteristics of this model include customer-service focused, establishing service levels, and the overall customer experience. This model relies heavily on customer feedback and interaction. In turn, this customer feedback is driven back into the organization in order to improve operations and product offerings. The second is what is referred to as the Project-Based model. This model can be viewed as smaller full-service groups that support a specific program, product, or project. This model relies heavily on crossfunctional teams and skills and tight integration of people, processes, and technology (Cao, 2004).

\section{Key Functions}

Some of the key functions that support any Service Delivery organization (Jui-Sheng et al., 2011), regardless of the operational model include account management, service management, technical support, material management, and operations (Ivanov, 2010). The primary differences between the Customer-Centric and ProjectBased models are the Customer-Centric model focuses on customer behavior, feedback, opinion, and assessment as critical driving elements and with the Project-Based model the model operates on a program, product, or project level focused on delivering bundled services and solutions.

\section{Core Processes}

Some of the more common core processes that support any Service Delivery organization, regardless of the operational model, include order fulfillment, repair, returns, maintenance, engineering, planning, shipping, receiving, inventory, implementation, integration, and testing.

\section{Framework}

The proposed framework focuses on more of a "functions" centric model. The model is employable whether the entity is a manufacturing or service-oriented organization. Regardless of the type of organization that 
performs these functions, one or many - depending on the size of the organization - can still be accomplished successfully. By taking a more functional view, this focus enables the threading of the key areas of the organization. Figure 1 illustrates the Operations Strategy framework.

\section{Operations Strategy Framework}

\section{Operations Strategy is the integration and optimization of operational functions and processes with market and customer requirements}

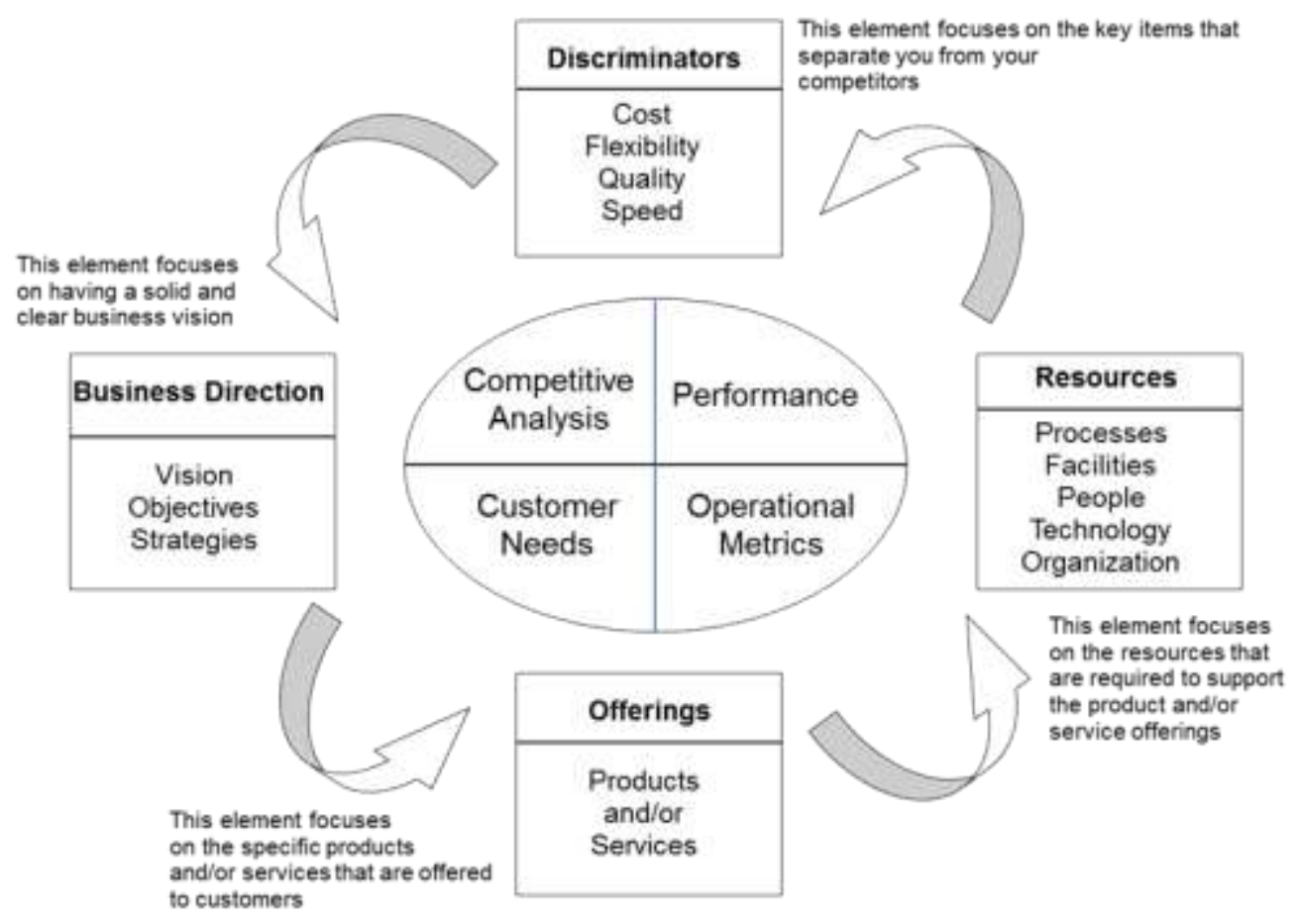

Figure 1: Operations Strategy Framework

\section{Business Direction}

A solid vision, objectives, and strategies serve as the foundation and blueprint for the organization. The vision, objectives, and strategies must come from the organization. Without these critical elements, the organization does not have an objective or target environment in which it can achieve.

A vision is not a mission statement and it does have an end-point. Objectives are the goals that the organization wants to achieve, and strategies are how the organization will achieve those goals.

\section{Offerings}

Offerings are the products and services an organization markets to customers and consumers. Products and services need to be targeted and sometimes tailored to meet customer needs. They can also be bundled or unbundled to provide greater or enhanced value to the market.

\section{Resources}

Facilities, people, technology, organization, and even core processes are used to support the delivery of products and services. Having the correct balance of resources and people with proper training and skills that are 
leveraging technology and efficient processes are extremely important for an organization to remain effective and efficient.

\section{Discriminators}

There are a number of key elements that separate or distinguish an organization from its competitors. Cost, flexibility, quality, application of innovation, and speed are crucial criteria that determine competitive advantage. Discriminators must be carefully analyzed to determine how an organization's competition will respond to market and customer reaction and stimulus (Garrido, 2007).

\section{Assessment}

The proposed Operations Strategy Tool links the functional areas of the organization to ensure that all functions are threaded throughout the entire organization. It can be used in capturing the current state of the organization as well as a strategic planning tool. Figure 2 illustrates the Operations Strategy Assessment Tool.

\section{Operations Strategy Assessment}

The Operations Strategy Assessment can be used as an effective decision-making tool that assists in determining the integration and connectivity throughout the entire organization

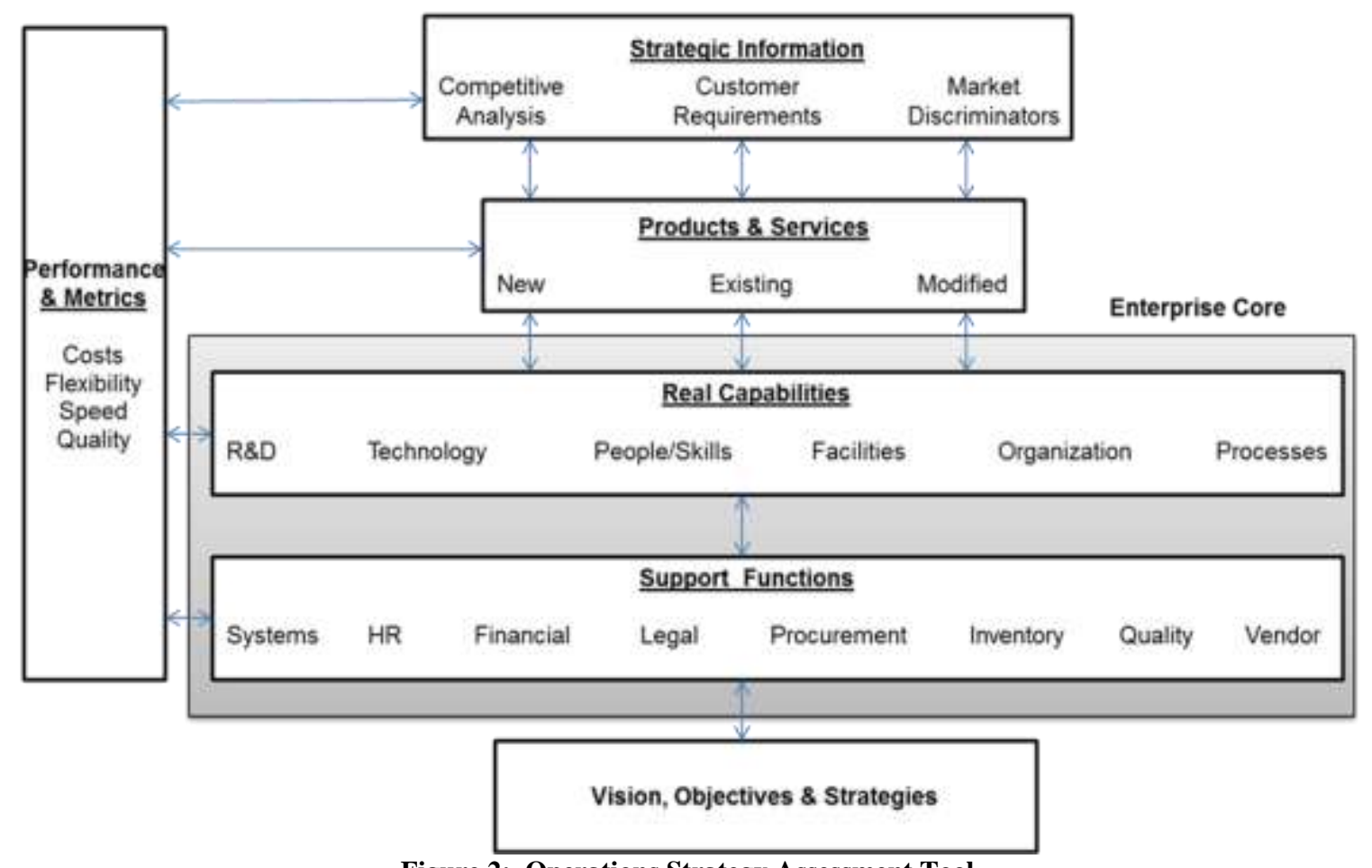

Figure 2: Operations Strategy Assessment Tool

\section{Strategic Information}

Performing a thorough competitive analysis, assessing the marketplace, and analyzing customer requirements can provide the market discriminators that an organization needs to be competitive in the market (Schniederjans \& Cao, 2009). This competitive analysis must be reviewed and updated on a consistent basis in order to observe changes in a competitor's behavior, actions, and product offerings. Customers should be frequently sampled to determine changes in needs and purchasing trends. Performance and metrics should be applied to all 
strategic information that is gathered. The results of the analyses and metrics will help an organization compare itself to its competitors.

\section{Products and Services}

Based on the strategic information and analysis, an organization must assess whether a new, existing, or modified product or service will fill the needs of the customer or consumer. This must be carefully determined and an organization should always look to see if an existing, or even a modified, product or service can be used to fill the marketplace needs. New products should be strategically planned and forecasted only when existing products and services cannot adequately fill requirements in the marketplace. A longer range planning cycle should be considered when developing new products and services to allow greater development, testing, and introduction time before the product or service is ready to market. Performance and metrics should be used to determine how an organization's products and services meet or exceed customer needs and requirements (Lukas et al., 2013).

\section{Real Capabilities}

Research and development, technology, people, skills, facilities, organization structure, and core processes are all leveraged to provide effective and efficient products and services. These functions really serve as the core functions that directly impact the delivery of products and services. The use of performance and metrics is critical in order to determine both economies of scale and scope as well as how efficient an organization delivers products and services.

\section{Support Functions}

A number of functions, such as information systems, human resources, finance, legal, procurement, and vendor relations, directly support the real capabilities in an organization. These are every bit as critical as the real capabilities and must be optimized to support the effective and efficient delivery of products and services. Performance indicators and metrics need to be applied to support functions in a similar manner as real capabilities. Many inefficient and ineffective operations can be hidden in these support-related functional areas and, as a result, increase overall costs can directly impact the delivery of products and services.

\section{Performance and Metrics}

Performance and metrics should be implemented and include costs, flexibility, speed, and quality to measure organizational effectiveness, both internally and externally. These metrics can help compare the organization against strategic information about competitors, customer expectations, and how the products and services compare to similar ones in the market. Internal metrics can also determine how effective and efficient an organization's real capabilities and support functions are performing with respect to the market and the product and service it is delivering. More importantly, the proper use of metrics can highlight imbalances and unproductive operations and processes throughout the organization (Lukas, et al., 2013).

\section{Vision, Objectives and Strategies}

Business direction is perhaps the most crucial. All of the strategic information, products and services, real capabilities, and support functions should be aligned to support the vision, objectives, and strategies of the organization (Corbett, 2008). Without solid and clear business direction that is cascaded down throughout the entire organization, people, processes and technology will not be aligned to support the effective and efficient delivery of products and services to the customer.

\section{Service Level}

Establishing and maintaining service levels is critical to the overall success of a service delivery organization. Defining and implementing a Service Level Agreement (SLA) with a customer can help ensure that specific levels of operational performance are consistently maintained and managed. SLAs can be used to define 
system availability, service response times, resource performance, service restoration parameters, and even hours of operation.

\section{Operating Performance}

Operating performance is the heart and focus of a solid operations strategy. Business direction, products and services, and resources need to be in alignment in order to perform and operate at a high-level of efficiency. Operating performance can be measured in many ways to include financial, product margins, customer satisfaction, and service quality.

From a financial standpoint, overall performance for a product or service can be measured by using the ratio between profitability and its sales. Another approach is using what is referred to as a Key Performance Indicator (KPI). The use of a KPI measurement system provides a much wider view and can cover a number of other functions and areas, not just the financial aspects of the organization.

Quality

Having a sound quality program is paramount to ensure that processes, products, services, and organizational functions are delivering the best possible value to the customer. Quality must be integrated or threaded throughout the organization. It cannot be a downward directed initiative or used as a short-term fix. In other words, quality must be as normal as performing everyday business operations.

Quality is the responsibility of every employee, not just a specific group within an organization. Companies that embrace quality will find it can often be used as a competitive advantage. Not only will it improve internal operational effectiveness, but it will also lead to higher customer satisfaction. Some organizations treat quality as a program or initiative and eventually do not realize the full benefits it can deliver. Developing a culture of quality will positively impact an organization's products, services, and profitability.

\section{Customer Expectations}

If there is one thing that can adversely impact an organization, it is to not effectively manage customer expectations. It is perhaps one of the most well-known issues, but one that is not often considered in operations strategy. An organization must actively pursue establishing continuous communications with a customer, as well as listen and act upon their input. Many different techniques can be used - surveys, polls, score cards, questionnaires, and even discussion groups - to keep information and feedback flowing between the customer and provider.

Another aspect of managing customer expectations is to ensure that the organization presents a clear and crisp understanding of the product or service being delivered. Not having a clear understanding of what is being delivered can be detrimental to an organization. It can also result in expending enormous costs to remedy the issue as well as severely reduce customer perception and satisfaction. Having a solid understanding of products and services being delivered, agreements, meeting requirements, and open communications are a few things that will help reduce and even negate confusion and lowered expectations.

\section{Growth}

Nearly every organization has a vision and sets goals in order to grow its products and services. However, growth can impact an organization in both a positive and negative manner. Primarily, this is a result of not properly managing growth and allowing it to occur either too slow or at a rapid pace.

Allowing growth to occur at a slow rate of speed can impact an organizations ability to deliver timely products and services, as well as to not keep up with market demand. On the other hand, extremely rapid growth can cause both financial and resource instability across the entire organization. Proper and judicious assessment and control, and using a solid set of metrics will greatly enhance the probability of successful and timely expansion. The key to successful and steady growth is balancing, and aligning market needs and customer requirements with the organization's internal operations, processes, and financial profile. 


\section{Added Services and Capabilities}

Adding additional products and services to an organization's offerings can provide a path for growth and expansion (Olhager, 2012). An organization must however, have a thorough understanding of its existing products and services. Prior to adding any additional capabilities, an organization must carefully analyze the impact they will have across the entire organization. This includes facilities, people, technology, processes, and organizational structure.

After the decision is made to expand products and services, the initiative should be treated as if it is a major project or initiative. Furthermore, a project management methodology should be applied to continuously monitor, assess, and manage the entire life-cycle process for the product or service. Risks should be identified, a project plan developed, metrics collected and analyzed, and deliverables and milestones carefully managed (Lukas, et al., 2013). Cost and schedule variances, both positive and negative, need to be immediately identified and resolved. The action will ensure the project is on track and the added services and capabilities are being properly integrated throughout the organization.

\section{Offshoring}

Offshoring and outsourcing are not new concepts. They have been implemented for decades by the electronics and automobile manufacturing market sectors. In order for these concepts to be successful, they must be treated just like making a personal financial investment. Since another or external firm will be relied upon to develop and support a product or service, they must be tightly coupled with the parent organization. In other words, they must be integrated with the parent organization's operations and processes.

Performing a detailed analysis prior to making a decision to offshore production is key as is selecting the right partner, and consummating a solid business agreement will greatly enhance the probability of success. Once the effort is engaged, monitoring the operation needs to be accomplished on a recurring basis not just at the beginning of the effort. Keep in mind that just because the product or service is outsourced or sent offshore, it does not mean the parent organization is resolved from its responsibility of providing a quality product or service for its customers. In fact, the same rigor or expectations an organization would require from its internal functions must be applied to the supplier organization.

\section{SUMMARY}

The proposed Operations Strategy Framework and Tool provide a broader functional view of the organization rather than a detailed process view. The concept is that organizations need to thread the entire organization's focus on the customer; thus, the strategy can be used to ensure that all functions are facing in that direction.

The framework and tool concept also broadens the traditional view of an organization to include an integrated view of the vision, objectives, strategies; people, process, technology; and performance, innovation and productivity. The strategy tool provides an approach that can be used to thread the organization. The tool can also be used to capture the "as-built" state to determine the gaps and inconsistencies throughout the organization. Finally, the tool provides a very top-level operational view of the entire organization which can be invaluable to strategic planning initiatives.

\section{AUTHOR INFORMATION}

Dr. Philip E. Burian, CM, CMQ/OE, is currently a Professor of Business Administration at Briar Cliff University, Sioux City, Iowa. Dr. Burian was previously the Chair of the Business and Management Department at Colorado Technical University in Sioux Falls, South Dakota. Dr. Burian has held various academic rolls to include adjunct faculty, Dissertation Chair, and Department Chair. He received his doctorate in 1997 from Colorado Technical University in Management. Dr. Burian has over 30 years of experience in the military and with industry in various 
leadership positions from startup to Fortune 500 companies. He holds a MA degree in Management from Webster University as well as a BS in Electronics and Technology from Chapman University. E-mail: Philip@ briarcliff.edu

Dr. Francis R "Skip" Maffei III is currently the Chair of Graduate Programs, School of Business, Jones International University (JIU). Dr. Maffei comes to JIU after 5+ years as a Program Director for an online university. He received his doctorate in 1997 from Colorado Technical University in Management and is a graduate of the Defense Acquisition University's Program Manager certification program. Dr. Maffei has over 25 years of experience in the military in various leadership and management related positions. He holds an MS degree in Logistics Management from Florida Institute of Technology as well as a BS in Industrial Management from the University of Akron. E-mail: frmaffei@msn.com

\section{REFERENCES}

1. Brown, S., Squire, B., \& Lewis, M. (2010). The impact of inclusive and fragmented operations strategy processes on operational performance. International Journal of Production Research, 48(14), 4179-4198. doi: 10.1080/00207540902942883.

2. Cao, Q., \& Schniederjans, M. J. (2004). Empirical study of the relationship between operations strategy and information systems strategic orientation in an e-commerce environment. International Journal of Production Research, 42(15), 2915-2939. doi: 10.1080/00207540410001691884.

3. Corbett, L. M. (2008). Manufacturing strategy, the business environment, and operations performance in small low-tech firms. International Journal of Production Research, 46(20), 5491-5513. doi: 10.1080/00207540701393163.

4. $\quad$ Edson Pinheiro, d. L., Sérgio Eduardo Gouvêa, d. C., \& Avides Reis, d. F.(2009) Taking operations strategy into practice: Developing a process for defining priorities and performance measures. International Journal of Production Economics, 122, 403-418. doi: 10.1016/j.ijpe.2009.06.022.

5. Garrido, E. D., Martín-Peña, M. L., \& García-Muiña, F. (2007). Structural and infrastructural practices as elements of content operations strategy. the effect on a firm's competitiveness. International Journal of Production Research, 45(9), 2119-2140. doi: 10.1080/00207540600735480.

6. Ivanov, D. (2010). An adaptive framework for aligning (re)planning decisions on supply chain strategy, design, tactics, and operations. International Journal of Production Research, 48(13), 3999-4017. doi: 10.1080/00207540902893417.

7. Jui-Sheng Chou, Kim, C., Yao-Chen Kuo, \& Nai-Chi Ou. (2010) Deploying effective service strategy in the operations stage of high-speed rail. Transportation Research Part E, 47, 507-519. doi: $10.1016 / j . t r e .2010 .12 .004$.

8. Lillis, B., \& Sweeney, M. (2012) Managing the fit between the views of competitive strategy and the strategic role of service operations. European Management Journal, doi: 10.1016/j.emj.2012.10.001.

9. Lukas, B. A., Whitwell, G. J., \& Heide, J. B. (2013). Why do customers get more than they need? how organizational culture shapes product capability decisions. Journal of Marketing, 77(1), 1-12. Retrieved from http://search.ebscohost.com/login.aspx?direct=true\&db=bth\&AN=84508931\&site=eds-live

10. Olhager, J., \& Johansson, P. (2011) Linking long-term capacity management for manufacturing and service operations. Journal of Engineering and Technology Management, 29, 22-33. doi: 10.1016/j.jengtecman.2011.09.003.

11. Rosenzweig, E. D., Laseter, T. M., \& Roth, A. V. (2010). Through the service operations strategy looking glass: Influence of industrial sector, ownership, and service offerings on B2B e-marketplace failures. Journal of Operations Management, 29(-), 33-48. doi: 10.1016/j.jom.2010.04.003.

12. Schniederjans, M., \& Cao, Q. (2009). Alignment of operations strategy, information strategic orientation, and performance: An empirical study. International Journal of Production Research, 47(10), 2535-2563. doi: $10.1080 / 00207540701673465$. 